\title{
Clinical Outcomes and Adverse Events Following Transforaminal Interbody Fusion for Lumbar Degenerative Spondylolisthesis in Elderly Patients
}

\author{
Toshiyuki TAKAHASHI, ${ }^{1}$ Junya HANAKITA, ${ }^{1}$ Manabu MinAMI, ${ }^{1}$ \\ Yoshihiro KITAHAMA, ${ }^{1}$ Keita KURAISHI, ${ }^{1}$ Mizuki WATANABE, ${ }^{1}$ \\ Yasuhiro TAKESHIMA, ${ }^{1}$ and Toshio UESAKA ${ }^{1}$
}

${ }^{1}$ Spinal Disorders Center, Fujieda Heisei Memorial Hospital, Fujieda, Shizuoka

\begin{abstract}
Transforaminal lumbar interbody fusion (TLIF) procedure is widely used, but the surgical indications for TLIF in elderly patients remain controversial because of potential risks such as inferior bone quality and higher rate of postoperative complications. Clinical efficacy and operative risk of TLIF in elderly patients are unclear. This study investigated the clinical effect and safety of TLIF for lumbar degenerative spondylolisthesis with radiculopathy or neurogenic claudication in patients aged 70 years or older. The clinical records were retrospectively reviewed of 35 consecutive patients aged $70-86$ years (mean 74.8 years) who underwent one or two-level TLIF. The preoperative diagnosis included degenerative spondylolisthesis with segmental instability. Clinical outcomes were assessed by the Japanese Orthopaedic Association score, visual analogue scale, Oswestry Disability Index. Radiological fusion rate was also investigated. Clinical and radiological results were compared with those of 43 younger patients. Clinical outcome measures were significantly improved after operation in the elderly patients, but improvement rates were significantly lower than those of younger patients. Fusion rate was similar in both groups. Overall postoperative complications were increased in aged patients, although the prevalence of complications directly related to surgical technique was not significantly increased. Postoperative complications not related to the surgical procedure were factors affecting poor results. TLIF is acceptable for achieving clinical recovery and lumbar fusion with high radiographic fusion success even in elderly patients, although clinical benefits were limited compared with those of younger patients. Postoperative morbidity was mainly related to general or non-operative site complications.
\end{abstract}

Key words: adverse event, elderly patient, lumbar spine, transforaminal interbody fusion

\section{Introduction}

Interbody arthrodesis supported by intervertebral and transpedicular instrumentation is generally acceptable for the treatment of lumbar degenerative disease with spinal instability, although the rationale and the appropriate technique for spinal fusion remain controversial. Lumbar interbody fusion provides immediate structural support, restores disc height, and maintains spinal alignment, resulting in successful clinical result and high fusion rate. ${ }^{20)}$ However, lumbar interbody fusion with intervertebral spacers is rarely reported in elderly patients, ${ }^{17,22)}$ and the surgical indications and outcomes for aged patients have not been established. Morbidity is frequently associated with lumbar

Received June 14, 2011; Accepted August 15, 2011 arthrodesis in elderly patients, so the potential risks of postoperative complications after lumbar interbody arthrodesis may be increased by agerelated comorbidities or intolerance of invasive surgery. ${ }^{6,8,9,24)}$ Several complications can be associated with the use of interbody support for anterior column reconstruction in the presence of aged bone fragility, which can lead to loss of disc height, local kyphosis, pseudoarthrosis, and failure of implanted instrumentation. Multiple approaches allow access to the interbody space, but transforaminal lumbar interbody fusion (TLIF) procedure can be applied to any level of the lumbar spine and does not require prolonged retraction of the neural structure. ${ }^{3,4,11,12)}$ However, the clinical benefits and operative risks of TLIF in elderly patients, such as low bone quality and inferior general condition, are not sufficiently understood. 
The present study investigated the clinical efficacy and safety of TLIF for lumbar degenerative spondylolisthesis with spinal instability in patients aged 70 years or older, and determined the factors related to poor clinical outcome.

\section{Clinical Materials and Methods}

The clinical records were retrospectively reviewed of 35 consecutive elderly patients who underwent one or two-level TLIF augmented with the pedicle screw fixation system from January 2005 to December 2007 at a single institute. The candidates were patients aged 70 years or older with symptomatic degenerative spondylolisthesis with radiculopathy or neurogenic claudication associated with segmental instability at the operated levels. Their general risks for anesthesia were grade I (healthy) or grade II (mild systemic disease without functional limitation) as classified by the American Society of Anesthesiologists physical status. Patients with previous history of back surgery, obvious ongoing psychiatric illness, or entitlement to worker's compensation were excluded. Minimum follow-up period was 24 months after surgery. Lumbar instability was based on evidence of dynamic sagittal translation of $5 \mathrm{~mm}$ or more and/or angulation of $10^{\circ}$ or more on flexion-extension films. Clinical outcomes were assessed by the Japanese Orthopaedic Association (JOA) score, visual analogue scale (VAS) between 0 (no pain) and 10 (maximal pain), the Oswestry Disability Index (ODI), and patient's satisfaction (satisfied, acceptable, and unsatisfied). These parameters were measured at baseline, 6 months, 12 months, 24 months, and the latest follow-up point after surgery. Postoperative clinical and radiological adverse events were assessed every 3 months for a year, and every 6 months thereafter until final follow-up examination. Radiological change of lumbar spinal alignment and fusion success rate was also investigated. Fusion success was confirmed by dynamic radiography obtained longer than 12 months after surgery, and was defined as presence of continuous intervertebral bone bridge between the fused segments on anterior-posterior radiography and lack of motion on flexion/extension films. Clinical and radiological results were compared with those of younger consecutive patients (43 patients) treated surgically under the same criteria during the same period. Clinical parameters such as operation time, surgical blood loss, length of hospitalization, occurrence of complications directly related or not related to the surgical procedure, and reoperation rate were compared between the two groups. Factors related to poor clinical results in the elderly group were also analyzed. Clinical data of the JOA score, VAS, and ODI were completely available in 30 $(86 \%)$ of the 35 elderly patients and 39 (91\%) of the 43 younger patients. The patients were followed up for a mean of 36.1 months (range 24-54 months).

The surgical procedure involved partial unilateral laminectomy and inferior facetectomy at the level of fusion. If the patients have central canal stenosis, bilateral intracanal decompression was performed through approach side. The titanium interbody spacer and bone chips obtained from the iliac crest were inserted into the intervertebral space after discectomy and curetting of the endplates through the facetectomy side. All patients received bilateral posterior pedicle screw-rod instrumentation with the Mykles system (Century Medical, Tokyo). The titanium interbody spacers were either E.I.V.S (Century Medical), IBS interbody device (Japan Medical Dynamic Marketing, Tokyo), or Capstone (Medtron-

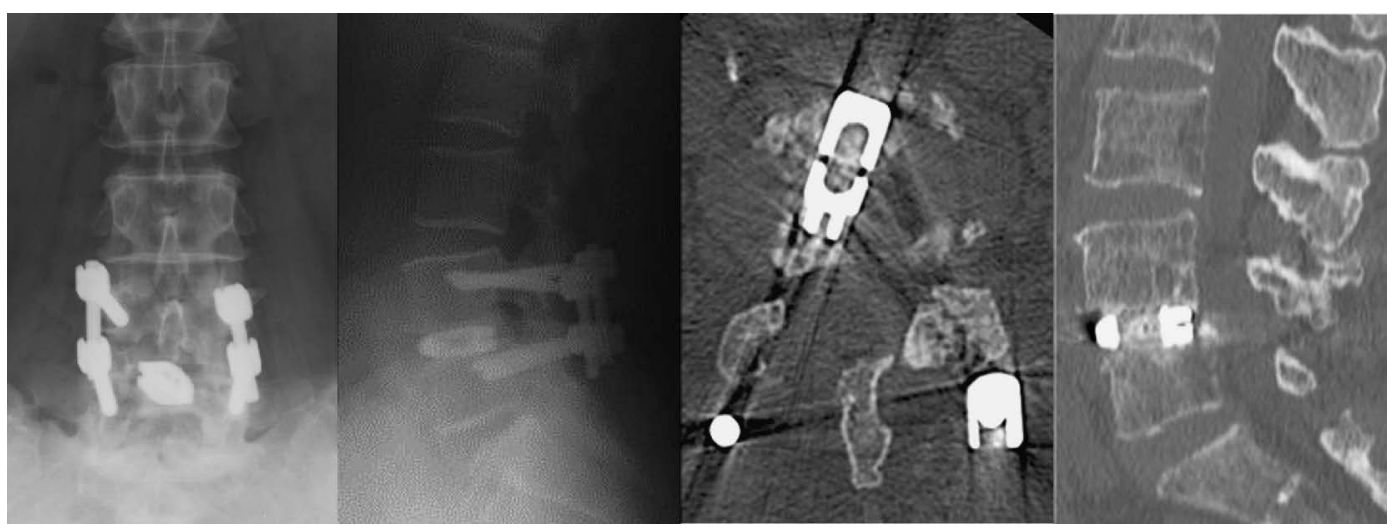

Fig. 1 Postoperative radiographs and computed tomography (CT) scans after transforaminal lumbar interbody fusion augmented with a pedicle screw fixation system. CT scans obtained 2 years after operation demonstrating osseous fusion at surgical site. 
ic Sofamor Daneck, Memphis, Tennessee, USA) (Fig. 1).

Statistical analysis was performed using the Mann-Whitney test, Fisher's exact test, and Wilcoxon's signed-ranks test. A probability value less than 0.05 was considered statistically significant.

\section{Results}

Table 1 summarizes the clinical characteristics of the elderly group and the younger group. The 18 male and 17 female patients in the elderly group were aged from 70 to 86 (mean 74.8 ) years. Thirtyfour patients underwent single-level fusion, and one patient had two-level fusions at L4-S1. Simultaneous decompression at the non-fused level was added in 7 patients to resolve symptoms of lumbar canal stenosis. The 18 male and 25 female patients in the younger group had a mean age of 58.6 years. No statistical difference was found between the two groups.

Neurological and functional recovery of all patients according to the JOA score, VAS, and ODI was significant at any time during the follow-up period in both groups (Fig. 2). However, the mean recovery rates of the JOA, VAS, and the ODI at final follow-up examination were $33 \%, 30 \%$, and $36 \%$ in the elderly group, and $61 \%, 75 \%$, and $46 \%$ in the younger group, respectively. The recovery rates of these clinical parameters were significantly lower in the elderly group $(\mathrm{p}<0.01)$. The patient satisfaction questionnaire found 22 of the 32 patients (69\%) reported satisfaction or acceptable for results of the surgical intervention in the elderly group whereas 40 of the 43 patients (93\%) in the younger group reported satisfaction.

Perioperative complications directly related to surgical maneuver occurred in three patients (8.6\%) in the elderly group. All three patients had woundrelated complications, including one seroma, one surgical wound dehiscence, and one hematoma at the posterior iliac crest bone graft harvest site. Postoperative general or other skeletal problems apparently not related to the surgical procedure were found in 9 patients $(25.7 \%)$ in the follow-up periods. Three lumbar compression fractures occurred in adjacent or remote sites to the fused vertebra. Three patients had worsened activity of daily living, two with chronic heart failure and one with cerebral infarction. One patient had deteriorated cervical spondylotic myelopathy and received cervical spine surgery. One patient had knee joint surgery due to aggravation of knee joint pain. One patient developed severe sacroiliac joint pain and needed intensive conservative therapy. The overall rate of complications was $34.3 \%$ in elderly patients. Reoperation was performed in 4 patients $(11.4 \%)$, including two additional decompressions of the adjacent level to the fused site, and two revision surgeries due to posterior migration of the interbody spacers. Table 2 summarizes the complications and reoperation in the elderly and the younger groups.

Radiological data was available from all patients for a minimum of 12 months postoperatively. Fusion success was observed in 34 of 36 fusion sites (94\%) in the elderly group and 44 of 45 fusion sites (98\%) in

Table 1 Summary of patient clinical characteristics and operative information in the elderly and younger groups

\begin{tabular}{lcc}
\hline & Elderly group $(\mathrm{n}=35)$ & Younger group $(\mathrm{n}=43)$ \\
\hline Age (year) & $74.8 \pm 4.3$ & $58.6 \pm 8.3$ \\
Sex & & 18 \\
male & 18 & 25 \\
female & 17 & $48.7 \pm 56.2$ \\
Duration of illness (month) & $43.2 \pm 36.3$ & $10(23 \%)$ \\
Smoking & $6(17 \%)$ & $7(16 \%)$ \\
Fused segment & & $31(72 \%)$ \\
L3-4 & $7(20 \%)$ & $3(7 \%)$ \\
L4-5 & $26(74 \%)$ & $2(5 \%)$ \\
L5-S1 & $1(3 \%)$ & $0(0 \%)$ \\
L2-3 + L3-4 & $0(0 \%)$ & $230 \pm 63$ \\
L4-5 + L5-S1 & $1(3 \%)$ & $198 \pm 105$ \\
Operation time (minute) & $237 \pm 67$ & $23.6 \pm 14$ \\
Blood loss (ml) & $173 \pm 92$ & $36.0 \pm 7.9$ \\
Length of hospital stay (day) & $25.6 \pm 19$ & 0.42 \\
Follow-up period (month) & $36.1 \pm 7.8$ & 0.46 \\
\hline
\end{tabular}

Age, duration of illness, operation time, blood loss, length of hospital stay, and follow-up period: mean \pm standard deviation. 

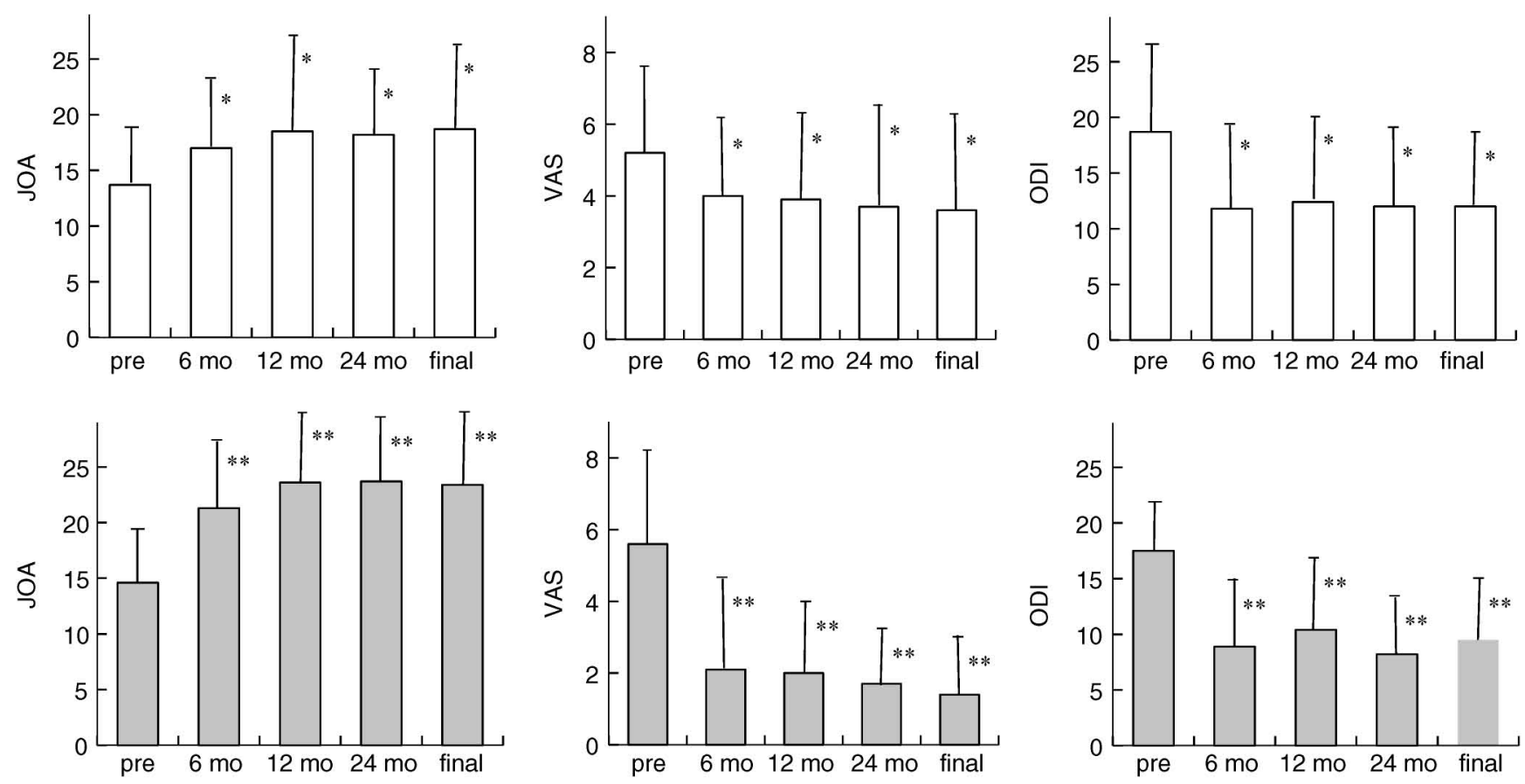

elderly patients

younger patients

Fig. 2 Bar graphs of the Japanese Orthopaedic Association (JOA) score, visual analogue scale (VAS), and Oswestry Disability Index (ODI) comparing preoperative (baseline) with postoperative assessment, and follow-up assessment scores in the elderly (upper row) and younger (lower row) groups. Asterisks indicate significant differences $\left({ }^{*} \mathbf{p}<0.05\right.$, ${ }^{* *} \mathbf{p}<\mathbf{0 . 0 1}$.

Table 2 Postoperative complications and reoperation in both groups

\begin{tabular}{lccc}
\hline & Elderly group $(\mathrm{n}=35)$ & Younger group $(\mathrm{n}=43)$ & $\mathrm{p}$ Value \\
\hline Complications related to surgery & $3(8.6 \%)$ & $4(9.3 \%)$ & 0.99 \\
minor root injury & 0 & 1 & \\
wound problems & 3 & 2 & $0.03^{*}$ \\
dural tear & 0 & 1 & \\
Complications not related to surgery & $9(25.7 \%)$ & $3(7.0 \%)$ & 0 \\
cerebral infarction & 1 & 0 & 0.69 \\
heart failure & 2 & 1 & \\
deterioration of CSM & 1 & 1 & \\
lumbar compression fracture & 3 & 1 & \\
hip joint disease & 0 & $3(7.0 \%)$ & 2 \\
knee joint disease & 1 & 1 & \\
sacroiliac joint pain & 1 & & \\
Reoperation & $4(1.4 \%)$ & 2 & \\
migration of implant & 2 & & \\
additional lumbar decompression & &
\end{tabular}

Asterisk indicates significant difference. CSM: cervical spondylotic myelopathy. 
the younger group. Lumbar alignment in sagittal or coronal planes was not changed postoperatively in both groups (Table 3).

Fourteen patients with less than $25 \%$ recovery in JOA score were regarded as having poor outcome. Age, sex, smoking, duration of illness, preoperative JOA score, bone mineral density of the lumbar spine, complications directly related to the surgical procedure, complications not directly related to the surgical procedure, and reoperation were analyzed as factors related to clinical outcomes. Only complications not directly related to surgical procedure were considered to cause unfavorable clinical results (Table 4).

\section{Discussion}

This study was conducted to clarify the clinical benefits and problems of TLIF for lumbar degenerative spondylolisthesis with segmental instability in elderly patients compared with non-elderly patients, and to investigate the factors associated with poor

Table 3 Fusion success rate and change in lumbar alignment in both groups

\begin{tabular}{lcc}
\hline & $\begin{array}{c}\text { Elderly group } \\
(\mathrm{n}=35)\end{array}$ & $\begin{array}{c}\text { Younger group } \\
(\mathrm{n}=43)\end{array}$ \\
\hline $\begin{array}{l}\text { Fusion success rate } \\
\text { L1-L5 sagittal angle }\left({ }^{\circ}\right)\end{array}$ & $34 / 36(94 \%)$ & $44 / 45(98 \%)$ \\
$\quad$ preoperative & $30.1 \pm 9.5$ & $33.7 \pm 12.8$ \\
$\quad$ postoperative & $29.4 \pm 8.0$ & $34.1 \pm 12.5$ \\
$\begin{array}{l}\text { L1-L5 coronal angle }\left({ }^{\circ}\right) \\
\quad \text { preoperative }\end{array}$ & $4.3 \pm 4.2$ & $3.6 \pm 2.9$ \\
$\quad$ postoperative & $4.5 \pm 4.1$ & $3.3 \pm 3.7$ \\
\hline
\end{tabular}

Preoperative and postoperative lumbar angle: mean \pm standard deviation. surgical outcome. Postoperative recovery was also assessed in both groups. TLIF is an alternative lumbar intervertebral fusion technique to posterior lumbar interbody fusion (PLIF). TLIF can be applied at any lumbar level because of minimal retraction of the dural sac, and preserves the midline lumbar posterior structures and contralateral facet joint through the familiar posterior approach. TLIF also achieves single-stage circumferential fusion augmented with the pedicle screw fixation system. The greatest advantage of TLIF is to reduce postoperative neuralgia, caused by intraoperative prolonged retraction of the lumbar roots, which sometimes occurs with conventional PLIF. ${ }^{13,21)}$

Clinical use of TLIF is increasing, $2,10,14,16,19,23,25-27)$ but only one report described the surgical results in elderly patients. Mini-open TLIF achieved $88.9 \%$ clinical success and $7.4 \%$ minor perioperative complications after single-level TLIF in patients aged 65 years or older, although nonunion of the fused segment and adjacent segmental deterioration occurred in $22.2 \%$ and $44.4 \%$, respectively, but these radiological adverse events did not affect the clinical results. ${ }^{17)}$ The less invasive TLIF procedure provided excellent clinical outcome in elderly patients, despite the inferior arthrodesis in the fused site. Another clinical study of lumbar interbody fusion in elderly patients indicated that the average JOA score significantly increased after PLIF and the average recovery rate was $63 \%$, with no obvious differences between elderly patients aged 70 years or older and younger patients, and postoperative complications occurred in $16 \%$ of elderly patients. ${ }^{22)}$ Our present study showed that TLIF was effective and safe for lumbar degenerative spondylolisthesis with segmental instability in elderly patients, but the clinical benefits were limited compared with those in youn-

Table 4 Clinical factors affecting poor surgical outcome in elderly patients

\begin{tabular}{|c|c|c|c|}
\hline & Poor outcome group $(n=14)$ & Good outcome group $(n=21)$ & p Value \\
\hline Age (year) & $75.5 \pm 4.8$ & $74.1 \pm 3.2$ & 0.30 \\
\hline Sex & & & 0.99 \\
\hline male & 6 & 12 & \\
\hline female & 8 & 9 & \\
\hline Smoking (\%) & 14.3 & 14.3 & 0.99 \\
\hline Duration of illness (month) & $48.1 \pm 38.5$ & $43.1 \pm 45.1$ & 0.30 \\
\hline Preoperative JOA score & $14.6 \pm 4.0$ & $13.4 \pm 4.5$ & 0.12 \\
\hline Bone mineral density $\left(\mathrm{g} / \mathrm{cm}^{2}\right)$ & $0.98 \pm 0.24$ & $1.06 \pm 0.19$ & 0.29 \\
\hline Complications related to surgery (\%) & 7.1 & 9.5 & 0.99 \\
\hline Complications not related to surgery (\%) & 42.9 & 9.5 & $0.04^{*}$ \\
\hline Reoperation (\%) & 21.4 & 4.7 & 0.27 \\
\hline
\end{tabular}

Age, duration of illness, preoperative Japanese Orthopaedic Association (JOA) score, and bone mineral density: mean \pm standard deviation. Asterisk indicates significant difference. 
ger patients. The average recovery rates of the JOA score, VAS, and ODI in elderly patients were about $30-40 \%$, significantly lower than in younger patients. Such improvements were quite different from a previous series in which the average recovery rates of VAS and ODI were $62 \%$ and $61 \%$, respectively. ${ }^{17)}$ Although the reasons for this discrepancy are not clear, some factors such as mean age, invasiveness of surgery, and bilateral interbody implants are presumably important.

Perioperative complications related to surgical procedure occurred in $8.6 \%$ of the elderly group in this study. This incidence is not high and all complications were minor. Therefore, the perioperative risk of interbody fusion is not regarded as serious. However, 9 patients (25.7\%) suffered from postoperative general or other skeletal problems not associated with the direct surgical procedure. Postoperative complications not directly related to the surgical procedure were significantly increased in the elderly group and influenced the poor outcome. The lumbar compression fractures occurring in adjacent or remote sites to the fused vertebra in 3 patients $(8.6 \%)$ after surgery are important problems. Reoperation rates in this study were almost the same in the elderly and younger groups. Finally, postoperative complications not directly related to the surgical procedure were only associated with poor clinical outcome in the elderly patients, so no predictive preoperative factors could be identified. In previous reports of surgical complication after lumbar arthrodesis, at least 1 major complication occurred in $21 \%$ and at least 1 minor complication in $70 \%$ of elderly patients. ${ }^{5)}$ A low rate of major complication (5\%) was reported after posterior decompression and fusion in elderly patients, but minor complication occurred in $30.7 \%$ of patients who underwent instrumented fusion procedures and $31.9 \%$ of patients who underwent noninstrumented fusion procedures. ${ }^{6)}$

The biomechanical and biological properties of the vertebral body are different in elderly and young patients. TLIF and PLIF in combination with pedicle screw fixation provide equivalent biomechanical stability in the human cadaveric spine. ${ }^{1)}$ The present study also investigated whether the position of interbody allograft in one-level TLIF affects the fusion rigidity. No biomechanical difference was identified in anterior or posterior column implantation of the allograft. More than $30 \%$ exposure of the endplate would be needed to achieve successful interbody fusion. In this experimental model, the exposed area of endplate proven by TLIF was $56 \%$, which was adequate to complete solid fusion, but was thought to be lower compared with PLIF.15) However, whether these facts are absolutely compatible in elderly patients is uncertain. The trabecular bone architecture is maintained longer in the lateral vertebral regions and the cortical bone becomes thicker in lateral regions with aging. ${ }^{7)}$ The best endplate region to place structural interbody support is the lateral position of lumbar spine based on a biomechanical study of regional endplate strength to compressive load. ${ }^{18)}$ Therefore, achievement of interbody fusion is likely to be influenced by bone quality as well as number, consistency, and location of interbody implants, especially in aged patients. Although our results suggested no significant inferiority of fusion success in the elderly group, a tendency of decreased fusion rate was observed compared to the younger group.

The present study showed that TLIF is an acceptable method for achieving clinical recovery and lumbar fusion with high radiographic fusion success even in elderly patients, although the clinical benefits were limited compared with those of younger patients. Postoperative morbidity was mainly related to general or non-lumbar site complications. However, all elderly patients were in good general condition and almost all patients underwent singlelevel instrumented fusion. The optimal technique for achieving lumbar arthrodesis in elderly patients remains unclear and further investigation is needed.

\section{Disclosure}

The authors report no conflict of interest concerning the materials or methods used in this study or the findings specified in this paper.

\section{References}

1) Ames CP, Acosta FL Jr, Chi J, Iyengar J, Muiru W, Acaroglu E, Puttlitz CM: Biomechanical comparison of posterior lumbar interbody fusion and transforaminal lumbar interbody fusion performed at 1 and 2 levels. Spine (Phila Pa 1976) 30: E562-566, 2005

2) Beringer WF, Mobasser JP: Unilateral pedicle screw instrumentation for minimally invasive transforaminal lumbar interbody fusion. Neurosurg Focus 20(3): E4, 2006

3) Blume HG, Rojas CH: Unilateral lumbar interbody fusion (posterior approach) utilizing dowel graft. J Neurol Orthop Surg 2: 171-175, 1981

4) Blume HG: Unilateral posterior lumbar interbody fusion: simplified dowel technique. Clin Orthop 193: 75-84, 1985

5) Carreon LY, Puno RM, Dimar JR $2^{\text {nd }}$, Glassman SD, Johnson JR: Perioperative complications of posterior lumbar decompression and arthrodesis. J Bone Joint Surg Am 85: 2089-2092, 2003

6) Cassinelli EH, Eubanks J, Vogt M, Furey C, Yoo J, 
Bohlman HH: Risk factors for the development of perioperative complications in elderly patients undergoing lumbar decompression and arthrodesis for spinal stenosis: an analysis of 166 patients. Spine (Phila Pa 1976) 32: 230-235, 2007

7) Cvijanovic O, Bobinac D, Zoricic S, Ostojic Z, Maric I, Crncevic-Orlic Z, Kristofic I, Ostojic L: Age- and region-dependent changes in human lumbar vertebral bone: a histomorphometric study. Spine (Phila Pa 1976) 29: 2370-2375, 2004

8) Deyo RA, Cherkin DC, Loeser JD, Bigos SJ, Coil MA: Morbidity and mortality in association with operations on the lumbar spine. The influence of age, diagnosis, and procedure. J Bone Joint Surg Am 74: 536-543, 1992

9) Deyo RA, Ciol MA, Cherkin DC, Loeser JD, Bigos SJ: Lumbar spinal fusion. A cohort study of complications, reoperations, and resource use in the Medicare population. Spine (Phila Pa 1976) 18: 1463-1470, 1993

10) Hackenberg L, Halm $H$, Bullmann V, Vieth V, Schneider M, Liljenqvist U: Transforaminal lumbar interbody fusion: a safe technique with satisfactory three to five year results. Eur Spine J 14: 551-558, 2005

11) Harms J, Rolinger H: [A one-stage procedure in operative treatment of spondylolistheses: dorsal tractionreposition and anterior fusion]. Z Orthop Ihre Grenzgeb 120: 343-347, 1982 (German)

12) Harms JG, Jeszenszky D: Die posteriore, lumbale, interkorporelle Fusion in unilateraler transforaminaler Technik. Oper Orthop Traumatol 10: 90-102, 1998 (German)

13) Humphreys SC, Hodges SD, Patwardhan AG, Eck JC, Murphy RB, Covington LA: Comparison of posterior and transforaminal approaches to lumbar interbody fusion. Spine (Phila Pa 1976) 26: 567-571, 2001

14) Jang JS, Lee SH: Minimally invasive transforaminal lumbar interbody fusion with ipsilateral pedicle screw and contralateral facet screw fixation. J Neurosurg Spine 3: 218-223, 2005

15) Javernick MA, Kuklo TR, Polly DW Jr: Transforaminal lumbar interbody fusion: Unilateral versus bilateral disc removal. An in vivo study. Am J Orthop (Belle Mead NJ) 32: 344-348, 2003

16) Lauber S, Schulte TL, Liljenqvist U, Halm H, Hackenberg L: Clinical and radiologic 2-4-year results of transforaminal lumbar interbody fusion in degenerative and isthmic spondylolisthesis grade 1 and 2 . Spine (Phila Pa 1976) 31: 1693-1698, 2006

17) Lee DY, Jung TG, Lee SH: Single-level instrumented mini-open transforaminal lumbar interbody fusion in elderly patients. J Neurosurg Spine 9: 137-144, 2008
18) Lowe TG, Hashim S, Wilson LA, O’Brien MF, Smith DA, Diekmann MJ, Trommeter J: A biomechanical study of regional endplate strength and cage morphology as it relates to structural interbody support. Spine (Phila Pa 1976) 29: 2389-2394, 2004

19) Lowe TG, Tahernia AD, O'Brien MF, Smith DA: Unilateral transforaminal posterior lumbar interbody fusion (TLIF): Indications, technique, and 2year results. J Spinal Disord Tech 15: 31-38, 2002

20) McAfee PC, DeVine JG, Chaput CD, Prybis BG, Fedder IL, Cunningham BW, Farrell DJ, Hess SJ, Vigna FE: The indications for interbody fusion cages in the treatment of spondylolisthesis: Analysis of 120 cases. Spine (Phila Pa 1976) 30(6 Suppl): S60-65, 2005

21) Okuda S, Miyauchi A, Oda T, Haku T, Yamamoto T, Iwasaki M: Surgical complications of posterior lumbar interbody fusion with total facetectomy in 251 patients. J Neurosurg Spine 4: 304-309, 2006

22) Okuda S, Oda T, Miyauchi A, Haku T, Yamamoto T, Iwasaki M: Surgical outcomes of posterior lumbar interbody fusion in elderly patients. J Bone Joint Surg Am 88: 2714-2720, 2006

23) Potter BK, Freedman BA, Verwiebe EG, Hall JM, Polly DW Jr, Kuklo TR: Transforaminal lumbar interbody fusion: Clinical and radiographic results and complications in 100 consecutive patients. J Spinal Disord Tech 18: 337-346, 2005

24) Ragab AA, Fye MA, Bohlman HH: Surgery of the lumbar spine for spinal stenosis in 118 patients 70 years of age or older. Spine (Phila $\mathrm{Pa}$ 1976) 28: 348-353, 2003

25) Rosenberg WS, Praveen VM: Transforaminal lumbar interbody fusion: Technique, complications, and early results. Neurosurgery 48: 569-574, 2001

26) Salehi SA, Tawk R, Ganju A, LaMarca F, Liu JC, Ondra SL: Transforaminal lumbar interbody fusion: surgical technique and results in 24 patients. Neurosurgery 54: 368-374, 2004

27) Villavicencio AT, Burneikiene S, Bulsara KR, Thramann JJ: Postoperative complication in transforaminal lumbar interbody fusion versus anteriorposterior reconstruction for lumbar disc degeneration and instability. J Spinal Disord Tech 19: 92-97, 2006

Address reprint requests to: Toshiyuki Takahashi, MD, Spinal Disorders Center, Fujieda Heisei Memorial Hospital, 123-1 Mizukami, Fujieda, Shizuoka 426-8662, Japan. e-mail: heisei.t-taka@ny.tokai.or.jp 